This PDF is a selection from a published volume from the National Bureau of Economic Research

Volume Title: American Universities in a Global Market

Volume Author/Editor: Charles T. Clotfelter, editor

Volume Publisher: University of Chicago Press

Volume ISBN: 0-226-11044-3; 978-0-226-11044-8

Volume URL: http://www.nber.org/books/clot08-1

Conference Date: October 2-4, 2008

Publication Date: May 2010

Chapter Title: The Economics of University Science and the Role of Foreign Graduate Students and Postdoctoral Scholars

Chapter Author: Grant C. Black, Paula E. Stephan

Chapter URL: http://www.nber.org/chapters/c11595

Chapter pages in book: $(129-161)$ 


\title{
The Economics of University Science and the Role of Foreign Graduate Students and Postdoctoral Scholars
}

\author{
Grant C. Black and Paula E. Stephan
}

\subsection{Introduction}

Universities play an important role in the production of knowledge in the United States, authoring nearly 75 percent (fractional counts) of scientific and engineering articles written in the country. ${ }^{1}$ Within the university, research is often performed with the assistance of graduate students, postdoctoral scholars (postdocs), and staff scientists, many of whom are foreign-born and foreign-educated. Currently, for example, over 45 percent of graduate students enrolled in science and engineering (S\&E) are foreignborn and approximately 60 percent of postdocs are on temporary visas.

This chapter documents the presence and importance of graduate students and postdocs in US academic science. We are particularly interested in the role of the foreign-born and foreign-trained. We begin by examining the importance of teams in university research and then provide an overview of the way in which university research is financed and structured. Next we summarize trends in the number and proportion of foreign-born graduate

Grant C. Black is assistant professor of economics in the School of Business and Economics at Indiana University, South Bend. Paula E. Stephan is professor of economics at the Andrew Young School of Policy Studies, Georgia State University, and a research associate of the National Bureau of Economic Research.

We wish to thank Bill Kerr for graciously matching our database to his ethnic database, Kelly Wilkin for data assistance, and Mark Regets for supplying helpful information regarding postdoctoral scholars. Bill Amis, Charles Clotfelter, Harold Shapiro, and Michael Teitelbaum made useful comments on an earlier draft of this chapter as did participants at the conference "American Universities in a Global Market," held in Woodstock, Vermont, October 2008.

1. Universities also play a considerably smaller - though growing - role in invention. In 2005, universities produced 3.7 percent of all patents awarded to US owners. The underlying count of 2,725 represents a 50 percent increase over the number awarded to universities ten years earlier. (National Science Board 2008, appendix table 5-40). 
students and postdocs studying in the United States. To explore the role that postdocs and graduate students play in the production of knowledge we examine articles published in Science during a six-month period in 2007 and 2008 that have a US academic-based scientist as the last author. Through web searches we are able to determine the status (postdoc, graduate student, staff scientist, or faculty) of virtually all US coauthors. We also examine the ethnicity of the coauthors by applying an ethnic-name database and infer nativity from ethnicity. We conclude in section 4.6 , summarizing our results and discussing their implications for US universities and for the research enterprise.

\subsection{The Importance of Teams}

Research is rarely done in isolation, especially research of an experimental rather than a theoretical bent (Fox 1991). Scientists work in teams. One way of seeing how team size and collaboration have changed is to examine trends in co-authorship patterns among papers with one or more authors from a "top 110" US university. Adams et al. (2005) find that for this group, the mean number of authors per paper increased from 2.8 to 4.2 for the eighteen-year interval, ending in $1999 .^{2}$ The rate of growth was greatest during the period of 1991 to 1996, when use of e-mail and the Internet was rapidly accelerating.

The growth in authorship is due to a rise in the number of people working on a project within a given university as well as to an increase in the number of institutions - especially foreign institutions - collaborating on a research project. During the period 1988 to 2003, the number of addresses associated with a US-authored article grew by 37 percent and the number of foreign addresses more than tripled (National Science Board 2006, table 5-18). Despite this impressive increase, the growth in co-authorship is fueled more by an increase in the number of authors working at the same university than an increase in collaboration across universities, as evidenced by the fact that during the same period the number of names on an article grew by more than the number of addresses on an article (50 percent versus 37 percent).

Several factors contribute to the increased role that collaboration plays in research. First, the importance of interdisciplinary research and the fact that major breakthroughs often occur in emerging disciplines encourage collaboration. Systems biology, which involves the intersection of biology, engineering, and physical sciences, is a case in point. ${ }^{3}$ By definition, no one has all the requisite skills required to work in the area; researchers must rely on working with others. Second, and related, researchers arguably are acquir-

2. The study is restricted to articles in science and engineering having one or more authors from a top 110 US university.

3. Systems biology studies the relationship between the design of biological systems and the tasks they perform. 
ing narrower expertise over time in order to compensate for the educational demands associated with the increase in knowledge (Jones 2005). Narrower expertise, in turn, leads to an increased reliance on teamwork for discovery. Third, the rapid spread of connectivity, which began in the early 1980s with the adoption of BITNET by a number of universities and accelerated in the early 1990s with the diffusion of the Internet, has decreased the costs of collaboration across institutions (Agrawal and Goldfarb 2008; Winkler, Levin, and Stephan 2008). Another factor that fosters collaboration is the vast amount of data that is becoming available, such as that from the Human Genome Project (and the associated GenBank database). Although that is probably the best known, many other large databases have recently come on-line, such as PubChem, which as of this writing contained over 18,000 recorded substances, and the Worldwide Protein Data Bank (wwPDB), a worldwide depository of information regarding protein structures. ${ }^{4}$ The practice of sharing research materials also leads to increases in the number of authors appearing on an article.

Increased complexity of equipment also fosters collaboration. ${ }^{5}$ By way of example, in the Science database that we have assembled for this chapter, four co-authors are identified on web pages as electron microscopists. Barnett, Ault, and Kaserman (1988) suggest two other factors that lead persons to seek co-authors. One is the desire to minimize risk by diversifying one's research portfolio through collaboration; the other is the increased opportunity cost of time. An additional factor is quality. The literature on scientific productivity suggests that scientists who collaborate produce "better" science than do individual investigators (Wuchty, Jones, and Uzzi 2007; Andrews 1979; Lawani 1986). Some of the factors encouraging collaboration are new (such as connectivity) but growth in the number of authors on a paper is not. Wuchty, Jones, and Uzzi (2007) find that team size has grown in all but one of the $171 \mathrm{~S} \& \mathrm{E}$ fields studied during the past forty-five years.

Much university research occurs in a lab setting. How these labs are staffed varies across countries. For example, in Europe research labs are often staffed by permanent staff scientists, although increasingly these positions are held by temporary employees (Stephan 2008). In the United States, while positions such as staff scientists and research associates exist, the majority of scientists working in the university lab are doctoral students and postdocs. Stephan, Black, and Chang's study (2007) of 415 labs affiliated with a nanotechnology center finds that the average lab has twelve technical staff, excluding the principal investigator (PI). Of these, 50 percent are

4. The Large Hadron Collider (LHC) at CERN will create vast amounts of data. According to Kolbert $(2007,74)$, "If all the L.H.C. data were burned onto disks, the stack would rise at the rate of a mile a month."

5. At the very extreme are the teams assembled to work at colliders. The CERN's four colliders have combined team size of just under 6,000: 2,520 for the Compact Muon Detector (CMS.), 1,800 for the Atlas, 1,000 for ALICE, and 663 for LHCb (Overbye 2007). 
graduate students, 16 percent are postdocs, and 10 percent are undergrads. ${ }^{6}$ Some labs are quite large. A case in point is the Susan Lindquist lab at MIT, which has thirty-six members (excluding Lindquist herself) - twenty postdocs, seven graduate students, one visiting scientist, one staff scientist, three technicians, and four administrators. ${ }^{7}$

This way of staffing labs has been embraced in the United States for a variety of reasons. Pedagogically, it is an efficient training model. It is also an inexpensive way to staff laboratories. Moreover, and as faculty are not abashed to note, it provides a source of "new" ideas, especially given the relative young age of doctoral students and postdocs. To quote Trevor Penning, while serving as the Associate Dean for Postdoctoral Research Training at the University of Pennsylvania School of Medicine, "A faculty member is only as good as his or her best postdoc" (Penning 1998). In addition, funding is often more readily available for predoctoral and postdoctoral students than for staff scientists. The typical National Institutes of Health (NIH) grant, for example, supports both types of training, as do many other forms of grants. At least from the perspective of the National Science Foundation (NSF), it has been a conscious policy to fund students. Rita Colwell, the director of NSF from 1998 to 2004, said in an interview with Science that "In the 1980s, NSF asked investigators to put graduate students on their research budgets, saying it preferred to fund graduate students rather than technicians" (Science 1998). There is also the added advantage that postdocs and graduate students, with their short tenure, provide for more flexibility in the staffing of laboratories than do permanent technicians.

This model for staffing labs has undoubtedly contributed to the United States's eminence as a training center for both native and foreign-born students. It provides not only a hands-on learning experience but also financial support for graduate study and postdoctoral work, something that many other countries cannot provide.

\subsection{The Structure and Financing of University Labs and Research Groups}

Labs at US universities "belong" to the faculty PI, if not in fact, at least in name, as is readily seen by the common practice of naming the lab for the faculty member. A mere click of the mouse, for example, reveals that all of the twenty-six faculty at MIT in biochemistry and biophysics use their name in referring to their lab. ${ }^{8}$ Sometimes, as in the case of the Nobel laure-

6. Approximately a third of the PIs were affiliated with departments of engineering, a third with departments of chemistry, and the remainder with departments of physics.

7. The Linquist lab is large compared to the labs of her colleagues at MIT in biochemistry and biophysics, which have an average of 6.3 graduate students (median of 7) and average of 5.25 postdocs (median of 5).

8. Details regarding research and staffing are available for seventeen of the twenty-six via lab web pages. Three other faculty have web pages for their labs that are not fully developed. For the other six one can find reference to the name of their lab when searching the Internet. 
ate Philip Sharp, lab members and former members are referred to using a play on the PI's name - in this case "Sharpies."

It is common practice for labs to maintain web pages, discussing research focus, publications, funding, and so forth. Most pages provide pictures of people who work in the lab, sometimes in a group shot; in other instances individual shots are included. While most pictures are of a traditional nature, it is not uncommon for the photos to be on the humorous side or slightly over the edge. ${ }^{10}$

Lab pages also traditionally provide links to "people" or "personnel," which include a list of everyone working in the lab, from undergraduate students to graduate students, postdocs, and staff scientists. Technicians and administrators are also listed. Some pages list alumni of the labs.

Research is expensive. Personnel costs alone for a small-to-medium lab, composed of three Graduate Research Assistants (GRAs), one postdoc, one technician, and the PI are approximately $\$ 210,000$, including salaries and benefits but excluding the cost of buying out the PI's time for research. Each additional graduate student adds approximately $\$ 37,000$; each additional postdoc adds approximately $\$ 52,000 .{ }^{11}$ Additional expenses include the cost of supplies and equipment. For research in the life sciences, supplies can easily average $\$ 18,000$ per year per lab member, or add another $\$ 108,000$ to the costs for a lab of six including the PI (Pelekanos 2008). This excludes the cost of animals, which can be quite expensive. An off-the-shelf mouse costs between $\$ 17$ and $\$ 60$ (US) in 2009; mutant strains begin around $\$ 40$ and can go to more than $\$ 500$. The cost to recover a mouse from a strain that is only available from cryopreserved material starts at $\$ 1,900 .{ }^{12}$ With the large number of mice in use (over 13,000 are already published), the cost of mouse upkeep becomes a significant factor in doing research. Universities in the United States, for example, charged from $\$ .05$ to $\$ .10$ per day per mouse (mouse per diem) in 2000 (Malakoff 2000). ${ }^{13}$

9. In a similar manner, graduate students and postdocs working in Alexander Pines' lab at Berkeley are referred to as "pinenuts" and alumni are referred to as "old pinenuts" (http://waugh .cchem.berkeley.edu/people/).

10. The White Lab web page (Christina White, Department of Chemistry, University of Illinois) depicts White seated on a stone throne, engulfed in flames and surrounded by twelve of her graduate students, one of whom is sporting horns. See http://www.scs.uiuc.edu/white/.

11. The graduate student amount includes stipend, fringe benefits, and tuition and is based on the amount allowed by NIH for the Ruth Kirstein National Research Service Award (NRSA) Fellowship for fiscal year (FY) 2007. Many institutions pattern their support for other students on the Kerstein Fellowship. The postdoc figure includes stipend and fringe benefits; it is the average paid under NIH guidelines for postdocs with varying experience. The fringe amount comes from Pelekanos (2008), as does the cost estimate for the technician.

12. More than 67 percent of the Jackson Labs' four thousand strains are only available from cryopreserved material (correspondence with James E. Yeadon, $\mathrm{PhD}$, technical information scientist, the Jackson Laboratory, September 14, 2009).

13. This cost of mouse upkeep can rapidly add up. Irving Weissman of Stanford University reports that before Stanford changed its cage rates he was paying between $\$ 800,000$ and $\$ 1$ million a year to keep the 10,000 to 15,000 mice in his lab. Costs for keeping immune-deficient mice are far greater (on the order of $\$ .65$ per day), given their susceptibility to disease. 
Equipping a lab adds considerably more to expenses. Pelekanos (2008) estimates that start-up equipment for a lab in the life sciences costs about $\$ 60,000$. But equipment can cost much more than this. A microscope used for research in nanotechnology can cost $\$ 750,000$ (http://www.unm.edu/ $\sim$ market/cgi-bin/archives/000132.html). A sequencer, such as Illumina's Genome Analyzer System, for example, costs $\$ 470,000$. One reason research in certain fields is conducted outside the university relates to the extremely high cost of equipment and the indivisible nature of this equipment. At the extreme are costs associated with building and running an accelerator. The twenty-seven-kilometer-long Large Hadron Collider (LHC), which has recently come on-line at the European Organization for Nuclear Research (CERN), costs approximately $\$ 8$ billion; the Spallation Neutron Source (SNS) at Oak Ridge National Laboratory in the United States costs \$1.41 billion. (Service 2006).

In order to get started on an independent research career, faculty usually receive resources from the dean at the time they are hired. Included in these start-up-packages are funds for equipment and stipends to hire graduate students, staff scientists, and postdocs. Also, and of crucial importance in the lab sciences, they are assigned space. Ehrenberg, Rizzo, and Jakubson (2003) have surveyed US universities regarding start-up packages. They find that the average package for an assistant professor in chemistry is $\$ 489,000$; in biology it is $\$ 403,071$. At the high end it is $\$ 580,000$ in chemistry; $\$ 437,000$ in biology. For senior faculty they report start-up packages of $\$ 983,929$ in chemistry (high-end is $\$ 1,172,222$ ); and of $\$ 957,143$ in biology (high end is $\$ 1,575,000$ ).

Start-up packages are exactly that. After several years, the faculty member becomes responsible for procuring the resources for the lab. ${ }^{14}$ Faculty do this primarily through the grants system, writing proposals and, if successful, receiving funds from Federal agencies and private foundations. ${ }^{15}$ Faculty also receive support for their labs from industry. One exception to the rule is that faculty sometimes host postdocs who have received funding through a fellowship or graduate students supported on training grants (awarded to the department) who work (on a rotation basis) in a faculty lab. ${ }^{16}$ Increasingly, faculty are expected not only to cover the research expenses of the lab through grants and contracts, but also to cover a portion of their own salary. Indeed, it is becoming increasingly common for faculty in tenured

14. Start-up packages have been known to have unintended consequences. A chair of a department recounted to one of us that new hires in the department "hoard" their start-up funds, postponing going up for NIH funding until a tenure decision has been made.

15. The primary sources of federal funds are The National Institutes of Health (NIH), the Department of Energy (DOE), the Department of Defense (DOD), and, to a lesser extent, the National Science Foundation (NSF).

16. For example, MIT distinguishes between postdoctoral associates and postdoctoral fellows. The former are supported through grants that faculty have procured at MIT; the latter have received fellowships or stipends to work with a faculty member at MIT. 
positions at US medical institutions to be required to procure a portion of their salary from grants. ${ }^{17}$

Grant applications and administration divert scientists from spending time on research. A 2006 survey of US scientists found that scientists spend 42 percent of their research time filling out forms and in meetings; tasks split almost evenly between pre-grant (22 percent) and post-grant work (20 percent). The tasks cited as the most burdensome were filling out grant progress reports, hiring personnel, and managing laboratory finances (Kean 2006).

Organizationally, PI-labs in the United States are structured as pyramids. At the pinnacle is the faculty principal investigator. Below the PI are the postdocs; below the postdocs are graduate students and undergraduates. Some labs, as we note, also have scientists who have completed postdoctoral training in this or another lab and are hired in such non-tenure-track positions as staff scientists and research faculty. The pyramid analogy does not stop here, however. In certain ways the research enterprise itself resembles a pyramid scheme. In order to staff their labs, faculty recruit $\mathrm{PhD}$ students into their graduate program with funding and the promise of interesting research careers (Stephan and Levin 2002). Upon receiving their degree it is mandatory for students who aspire to a faculty position to first take an appointment as a postdoc. Postdocs then seek to move on to tenure-track positions in academe. The Sigma Xi study of postdocs, for example, found that 72.7 percent of the postdocs who were looking for a job were "very interested" in a job at a research university and 23.0 percent were "somewhat interested" (Davis 2005). In recent years, however, the transition from postdoc to tenure track has been slowed as the number of tenure-track positions has failed to keep pace with the increase in supply.

Faculty not only staff labs with graduate students and postdocs. They actively recruit and select the students who work in their lab. Unlike admission decisions to $\mathrm{PhD}$ programs, however, which generally occur at the department level, decisions regarding staffing are usually made by the faculty member who, in effect, is paying for the student.

Not surprisingly, given the role faculty play in staffing decisions, networks, or what may more accurately be described as "affinity effects," appear to play a role in staffing. Tanyildiz (2008) has studied paired labs in eighty-two departments of engineering, chemistry, physics, and biology. In each case she matches a lab directed by a "native" PI (as established by name and undergraduate institution) to a lab directed by a foreign PI, either of Chinese, Korean, Indian, or Turkish background. She then studies the graduate student composition of the labs, assigning nationalities to the students based on the common-name methodology used by Kerr (2008). She finds signifi-

17. A survey of medical schools found that tenure is accompanied with no financial guarantee for 35 percent of basic science faculty and 38 percent of clinical faculty (Bunton and Mallon 2007). 
cant differences in the role that ethnicity plays in staffing. The mean paired difference in the percent of Chinese students in a lab directed by a Chinese PI versus a lab in the same department directed by a "native" US faculty is 37.8 percent; that for Koreans is 29.0 percent; that for Indians is 27.1 percent; that for Turkish is 36.3 percent (very small sample). When she compares labs directed by natives to nonnatives from one of these four groups the mean paired difference is 28.9 percent. Clearly, clustering by ethnicity occurs in labs. Tanyildiz also finds that affinity effects are more common in "bottom"ranked departments; less common in "top" departments. ${ }^{18}$

Not all university research is organized around labs directed by faculty. In the earth sciences, for example, scientists often do not work in a lab setting. In instances of "big" science (such as experimental high energy physics, cosmology, and astrophysics), research is often organized around equipment such as a telescope or an accelerator. Often this equipment is located off-site, sometimes at national labs, such as the Stanford Linear Accelerator (SLAC), Fermi Lab, or the Lawrence Berkeley National Laboratory; sometimes it is located at international labs, as in the case of CERN. ${ }^{19}$

The absence of a lab on campus does not mean that graduate students and postdocs are absent nor that faculty lack a role in choosing who works with them or their group. In many instances of "big" science it is not uncommon for the group to have a web page named for its research focus - for example, the Caltech Observational Cosmology Group (with the goal of developing novel instruments) - which lists the research focus and links to faculty, postdocs, graduate students, visitors, and staff working in the group. Individual physicists in the group also maintain a web page, but physicists working in the area do not have labs with their name attached to the lab. But it is not only "big" physics that presents itself as a group. It occurs in other areas as well. For example, the Experimental Condensed Matter Research Group at $\mathrm{Cal}$ Tech keeps a group web page, as does the Spin Group and the Infrared Arm Group, to give but several examples. Moreover, it is not just experimentalists who speak of their group. Numerous examples can be found where theoretical physicists talk of their "group" on the web even though members of the group may be working by themselves.

18. Using NRC rankings, she finds that the mean difference is 25.9 percent in "top" departments, 35.9 percent in "middle" departments, and 53.2 percent in "bottom" departments. These calculations do not include mean differences between native students in native labs versus native students in nonnative labs.

19. By way of example, physicists at the California Institute of Technology routinely work at telescopes in New Mexico and Hawaii, and at SLAC. They also are playing key roles in developing the Compact Muon Solenoid (CMS), one of the two large general purpose particle physics detectors that will come on-line at CERN in 2008. 


\subsection{Trends in the Production of PhDs and Postdoctoral Students by Visa Status}

\subsubsection{PhD Awards}

In the early $1980 \mathrm{~s}$, approximately $12,000 \mathrm{PhDs}$ were awarded annually in the United States in science and engineering. By the late 1990s the number had grown to approximately 20,000; by the mid-2000s it had increased to over 23,000 , roughly doubling over the entire period. This substantial increase, however, masks wide differences in enrollment patterns among US citizens and noncitizens shown in figure 4.1 for the period from 1980 to $2006 .^{20}$

We see that the number of US students receiving S\&E PhDs grew by only 30 percent during the period. Moreover, virtually all of the growth that occurred was among women students. The number of $\mathrm{PhDs}$ awarded to citizen women increased by 170 percent from 1980 to 2006, while the number of US males receiving $\mathrm{PhDs}$ in science and engineering changed little during the period.

In contrast, the number of temporary residents receiving $\mathrm{PhDs}$ grew considerably, with the increase accounting for more than 67 percent of the growth in PhD production in the United States. Permanent residents played a much smaller role, contributing only another 2.3 percent. ${ }^{21}$ Growth of the foreign-born was especially strong during the mid-1980s to mid-1990s and again beginning in 2003. The number of foreign-born declined somewhat during the late 1990s and early 2000s.

Almost half of noncitizen PhDs come from the three countries of China, South Korea, and India (Hoffer et al. 2006, table 12). China's role has become so dominant that Tsinghua University and Peking University recently surpassed the University of California, Berkeley, as the most likely undergraduate institution for those earning a $\mathrm{PhD}$ at a US institution, regardless of nativity, between 2004 and 2006. ${ }^{22}$

The growth in the number of temporary residents receiving S\&E PhDs has been dramatic across most fields, as seen from figure 4.2. The percent of $\mathrm{PhD}$ recipients who were temporary residents at the time the degree was

20. For these data, science and engineering excludes medical and social sciences, citizen means a native or naturalized citizen of the United States, permanent resident means a noncitizen immigrant holding a green card indicating permanent residency in the United States, and temporary resident means a nonimmigrant visa holder planning to remain in the United States temporarily (such as a student or temporary worker).

21. The exception was the large increase in permanent residents in the early-to-mid 1990s, which, along with the accompanying decrease of temporary-resident recipients, reflects the passage of the Chinese Student Protection Act that permitted Chinese nationals temporarily residing in the United States to switch to permanent-resident status.

22. The calculations are for degrees awarded between 2004 and 2006 (Mervis 2008). The University of California, Berkeley, is now in third place, followed by South Korea's Seoul National University, Cornell University, and the University of Michigan, Ann Arbor. 


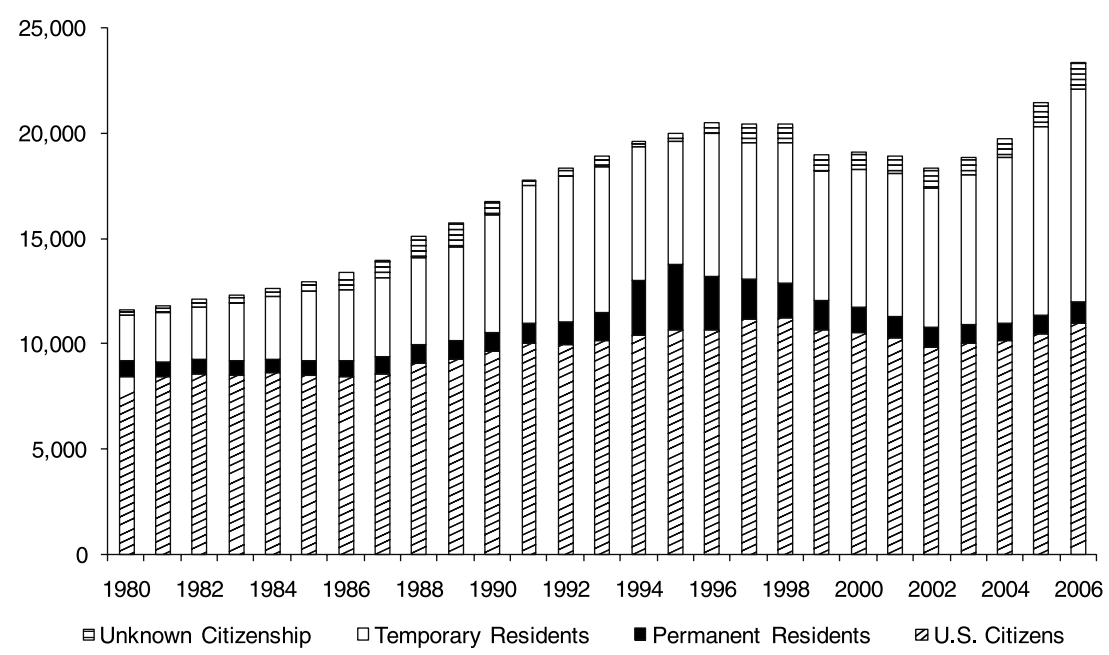

Fig. 4.1 S\&E PhDs awarded by citizenship status, 1980-2006

Sources: National Science Foundation, WebCASPAR database.

Notes: Data for figures 4.1 through 4.4 come from WebCASPAR. WebCASPAR is an online integrated database of data from US academic institutions emphasizing science and engineering. WebCASPAR includes data sources from the National Science Foundation and the National Center for Education Statistics. The National Science Foundation oversees the WebCASPAR database. WebCASPAR data used in this study originally come from NSF's Survey of Earned Doctorates and Survey of Graduate students and Postdoctorates in Science and Engineering (also known as the Graduate Student Survey, or GSS). Data used in figures 4.1 through 4.4 were selected from WebCASPAR based on status as a $\mathrm{PhD}$ recipient, graduate student, or postdoc; citizenship status; S\&E field; and year.

received more than doubled from 1980 to 2006 in the fields of math and computer sciences, the physical sciences, geosciences, and life sciences. These high growth rates dramatically increased the proportion of foreign-born receiving degrees in certain fields. For example, in math and computer sciences, the proportion rose from 19 percent to over 51 percent; in the life sciences, from approximately 12 percent to 27 percent. Growth in the number of degrees awarded to the foreign-born was lower in engineering, where temporary residents have long received a considerable share of degrees. By 2006 almost 60 percent of all $\mathrm{PhDs}$ in engineering were awarded to individuals on temporary visas.

The fields of the geosciences and the physical sciences owe most of their growth during the period to the large influx of foreign students. In the former, for example, temporary residents made up over 96 percent of the growth in number of degrees; in the latter, they comprised 92 percent. In terms of magnitude of change in the number of temporary residents receiving $\mathrm{PhDs}$, the greatest growth took place in the fields of engineering and the life sciences. In 1980 the number of engineering PhDs awarded to temporary residents was 861 ; by 2006 that number had risen to almost 4,300 . 


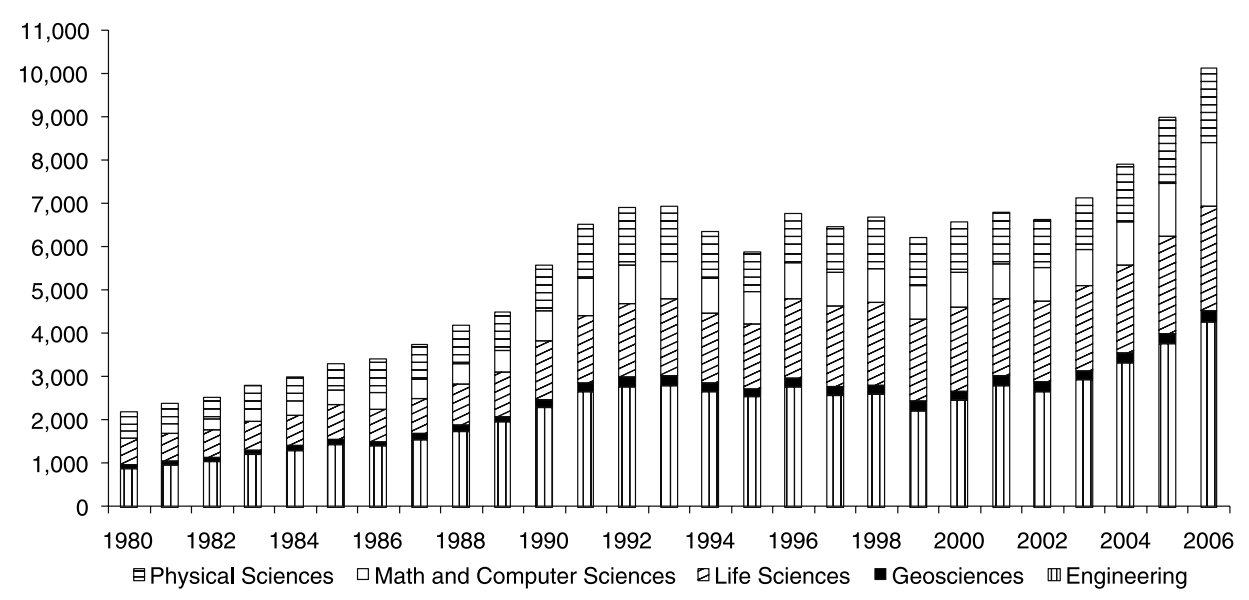

Fig. 4.2 Number of S\&E PhDs awarded to temporary residents by field, 1980-2006 Source: National Science Foundation, WebCASPAR database.

In the life sciences, almost 620 temporary residents received $\mathrm{PhDs}$ in 1980 compared to over 2,400 in 2006 . The latter was undoubtedly spurred by increased resources made available for the support of graduate students, which resulted from the doubling of the NIH budget in the late 1900s and early 2000 s.

\subsubsection{Recent Trends in Graduate Student Enrollments}

Data concerning the number of $\mathrm{PhDs}$ awarded reflect conditions and decisions made six to seven years prior to the award date. Thus, the increases that we have documented were put in motion long before 9/11. Following $9 / 11$, considerable attention was focused on the observed decline in applications and admissions of international graduate students and what this would mean for graduate education in the United States. For example, between 2003 and 2004 graduate applications across the board declined by 28 percent, admissions by 18 percent, and enrollments by 6 percent (National Academies 2005, 31). ${ }^{23}$ These concerns have been somewhat mitigated by the modest rise in the enrollment of international graduate students experienced recently. For example, according to the Survey of Graduate Students and Postdoctorates in Science and Engineering for 2006, first-time, fulltime enrollment for temporary residents in graduate science and engineering programs rose 16.4 percent between 2005 and 2006, compared to a mea-

23. Comparable figures for engineering are $-36.0,-24.0$, and -8.0 ; for the life sciences, -24.0 , -19.0 , and -10.0 ; and for the physical sciences, $-26.0,-17.0$, and +6.0. Data come from the Council of Graduate Schools (National Academies 2005, 31). It should be noted that application and admission data "double count" to the extent that students apply and are admitted to multiple programs. 
ger 1.7 percent for US citizens and permanent residents (National Science Foundation Web Computer-Aided Science Policy Analysis and Research [CASPAR]). It remains to be seen whether this turnaround will continue. Clearly, enrollment patterns are affected not only by US visa policy but also by opportunities for study outside the United States, which in recent years have been increasing.

\subsubsection{Postdocs}

Estimating the population of scholars working in postdoctoral positions in the United States is complex and leads to different measures based on the methodology that is employed. Thus, estimates must be read with caution. Complications arise from several factors, including survey sampling frameworks that omit or do not easily identify some postdocs, especially in nonacademic sectors, or those with doctorates from foreign institutions; the timing of survey data collection that can miss increasingly migratory S\&E PhDs; exclusions and discrepancies surrounding some S\&E occupations in certain standard surveys; and institutional difficulties in identifying workers as postdocs and by visa status (National Science Board 2008; Regets 2007). By way of illustration, Regets (2007) offers the anecdotal example of officials at a major research university who expressed confidence in their ability to identify all temporary-visa postdocs at their institution on the assumption that only J-1 visas were used for postdocs. It was later discovered that Labor Condition Applications - the first step in the H1-B visa process - had been filed by the university for several hundred "postdoctoral appointments." There is also the issue of job title. It is not uncommon for individuals who are essentially postdocs to be called by another title, such as research scientist. Classification problems such as this mean that many postdocs go uncounted because of a wide range of measurement issues. ${ }^{24}$

Figure 4.3 shows the number of postdocs working at academic institutions in science and engineering in the United States from 1985 to 2006, based on the Survey of Graduate Students and Postdocs. ${ }^{25}$ We see that in 1985 there were slightly more than 16,000 postdocs at academic institutions. Within a decade, that number had grown to over 25,000 , and by 2006 the number of postdocs had surpassed 34,000 - an increase of 110 percent from

24. The NSF is acutely aware of the many problems involved in measuring postdocs and is in the process of designing a new methodology to measure the number and characteristics of postdoctoral scholars in the United States.

25. These data are also based on science and engineering - excluding the medical and social sciences - and account only for postdocs identified by surveys of academic institutions with graduate programs in science and engineering. Although the majority of postdoctoral positions are at academic institutions, postdocs can also be found in other sectors. Using the 2006 Survey of Doctorate Recipients, Hoffer, Grigorian, and Hedbert (2008) estimate that 75 percent of postdocs in science, engineering, and health fields were at educational institutions, 12 percent were in government, 11 percent were at for-profit or nonprofit organizations, and 2 percent were at other types of institutions. 


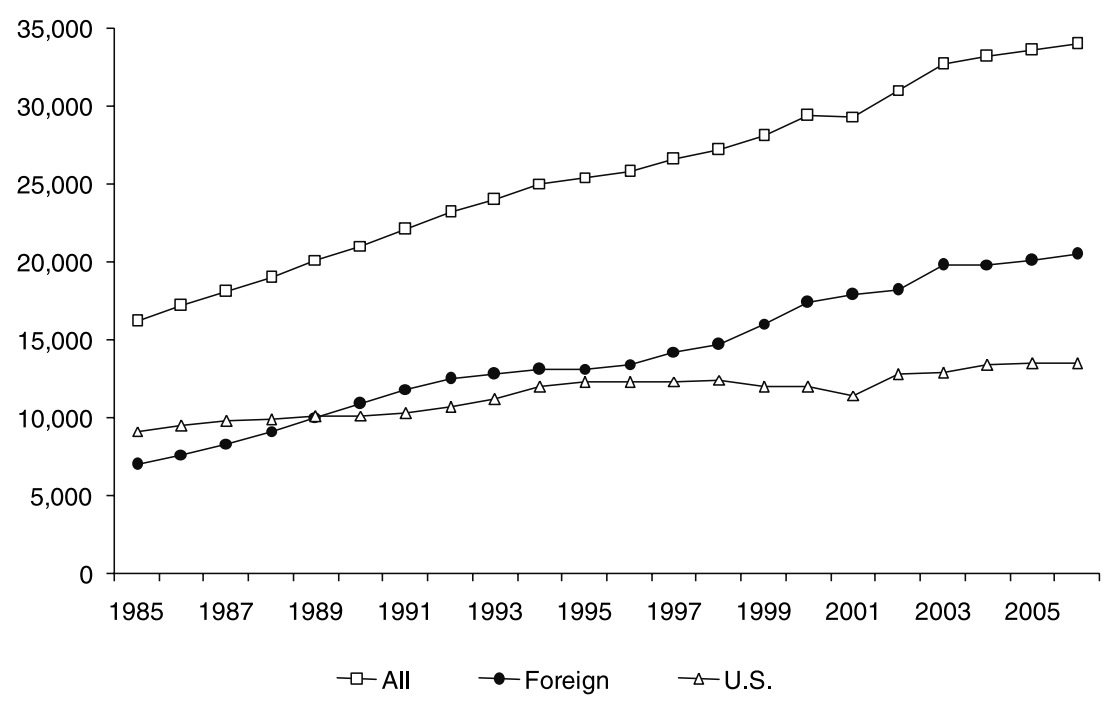

Fig. 4.3 Number of S\&E postdocs working in academe, 1985-2006

Source: National Science Foundation, WebCASPAR database.

1985 to 2006 . Growth was steady through the early 1990 s and continued to increase in the remainder of the 1990s, but at a slower rate. The number of postdocs declined slightly in 2001 but has since increased, particularly in 2002 and $2003 .{ }^{26}$

Growth in the number of postdocs has been fueled largely by scholars coming from abroad. The number of postdocs with temporary-resident visas (identified as foreign postdocs in figure 4.3) almost tripled between 1985 and 2006, rising from 7,032 in 1985 to 20,521 in 2006. While in 1985 temporary residents made up just over 43 percent of all postdocs, by the 2000 s they comprised approximately 60 percent of all academic postdoctoral scholars, reaching a peak of 61 percent in 2001. In contrast, the number of postdocs who are US citizens or permanent residents (identified as US postdocs in figure 4.3) grew by less than half during the same period. Indeed, the difference is so dramatic that from 1996 to 2006 alone, the number of temporary-resident postdocs grew by over 52 percent - more than the rate for U.S. citizens and permanent residents over the entire 1985 to 2006 period. The difference is so pronounced that temporary-resident postdocs grew at an annual rate of 5.2 percent, compared to only 1.9 percent for native and permanent-resident postdocs during the period. Tightened visa-security

26. The number of postdocs depends not only upon the propensity to take a postdoc but also upon the duration of the postdoc period of training. Stephan and Ma (2005) show that not only the propensity to take a postdoc but also the duration of the postdoc training period relate to the state of the academic labor market, suggesting that the postdoc position can become a "holding tank" where people wait for better market conditions. 
measures may have contributed to the slowdown in temporary-resident postdocs since 2003. In 2001, less than 8 percent of J-1 visa applications were denied; in 2003, almost 16 percent were refused (Regets 2005). ${ }^{27}$

While many postdocs earn their $\mathrm{PhD}$ in the United States prior to applying for a postdoctoral position, a remarkable number receive their $\mathrm{PhD}$ training outside the United States and come to the United States to take a postdoctoral position. Indeed, Regets (2005) estimates that almost five out of ten academic postdocs in the United States earned a doctorate in another country. Moreover, four out of five postdocs with temporary visas earned their doctorate outside the United States. ${ }^{28}$

Figure 4.4 shows the distribution of foreign S\&E postdocs by field for the period 1985 to 2006 . The dominant role of the life sciences is striking. For example, in 2006, close to six out of every ten postdocs on a temporary visa were in the life sciences. In terms of raw numbers, the figure shows that the life sciences also experienced the greatest growth in the number of postdoctoral positions held by those on temporary visas, going from 3,341 in 1985 to 11,694 in 2006. By way of contrast, the increase in engineering was 2,193 ; that in the physical sciences was 1,853 . The magnitude of the change in the life sciences is likely a result of the increased demand for postdocs in the field occasioned by the doubling of the NIH budget in the late 1990s and early 2000s. The fastest growth of postdocs on temporary visas occurred in the geosciences, where the number increased by a factor of more than six times. In math and computer sciences, the figure grew by over 300 percent. The number of temporary-resident postdocs grew by over 300 percent in math and computer sciences, 250 percent in the life sciences, 240 percent in engineering, and only 74 percent in the physical sciences.

\subsection{Authorship Patterns in Science}

To examine the contributions of postdocs, graduate students, and undergraduates to research in academe, we collected data on the authors of ar-

27. Foreign postdocs have traditionally been in the United States on either a $\mathbf{J}$ or an $\mathrm{H}$ visa, with some on F-1's for one year of optional practical training. The Sigma Xi survey (with a nonrepresentative sample) found that 51 percent of foreign postdocs were on J's, 41 percent on H's, and 3 percent on F-1s; the remaining 4 percent were on "other" visas (http://www .sigmaxi.org/postdoc/by_citizenship/). See also Davis (2005). Mark Regets reports (informal correspondence) that there is some evidence that the proportion on $\mathrm{H}-1 \mathrm{~B}$ visas has been growing, based on the number of Labor Condition Applications that explicitly contain the search string "postdoc." The number on F-1 visas is expected to grow, because optional practical training time was recently increased from twelve months to twenty-nine months for most S\&E advanced degrees.

28. These estimates are based on a comparison of counts from the National Science Foundation (NSF) Survey of Doctorate Recipients and the NSF Survey of Graduate Students and Postdoctorates in 2001. For example, in 2001, 17,900 academic postdocs with temporary visas were reported through the Survey of Graduate Students and Postdoctorates, while only 3,500 postdocs with temporary visas were reported in the Survey of Earned Doctorates, which only collects data on doctorates earned in the United States. Regets attributes the difference in these counts to postdocs, with $\mathrm{PhDs}$ earned outside the United States. 


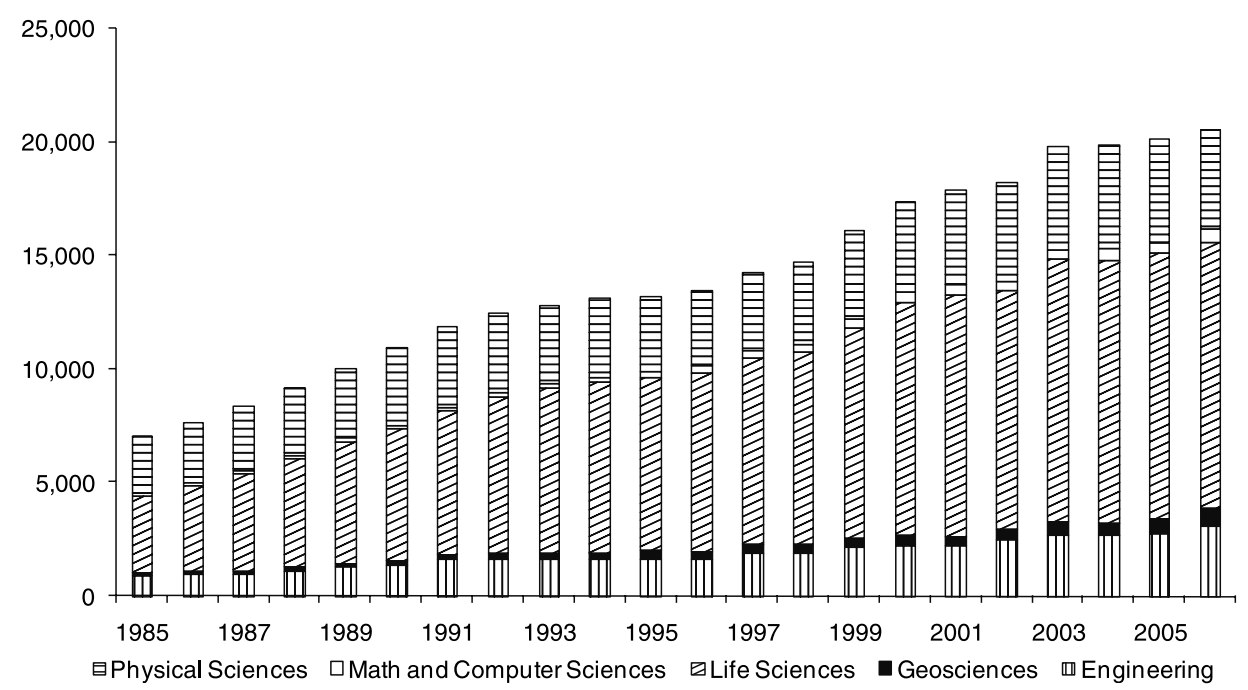

Fig. 4.4 Number of foreign S\&E postdocs by field, 1985-2006

Source: National Science Foundation, WebCASPAR database.

ticles published in Science from November 2, 2007 to May 2, 2008. ${ }^{29} \mathrm{We}$ focused on papers in the Research Articles and Reports sections of the journal. In many fields of science the last author is the principal investigator; while other rules or variations exist in terms of author order, we apply this common convention to our analysis to determine if a paper has a US origin. ${ }^{30}$ We further restrict the analysis to papers with a last author affiliated with a US academic institution, given our interest in studying science in academe.

We chose Science because of its multidisciplinary nature (the journal devotes 40 percent of its space to the physical sciences and 60 percent to the life sciences) and its position as a leading, if not the leading, journal in science. Moreover, and as is to be expected, the journal is highly selective. In 2007 the journal published 817 of the 12,450 articles that it received (6.6 percent; 461 of these (56.4 percent) had a first author from the United States (Franzoni, Scellato, and Stephan 2008).

For each paper we record the broad field related to the subject of the research, the number of authors, the name of each author, institutional affiliation as listed in the article, and the location (country) of the listed institutions. ${ }^{31}$ We collect additional information from Internet searches on

29. We code twenty-two issues for the six-month period. The four issues not coded are November 23 and 30 and December 7 and 14, 2007.

30 . Had we instead used the country of the first author to determine origin, the sample would have had 150 papers rather than the 159 papers we analyzed.

31. For publications with ten or more authors (twenty-six of the 159 US papers), only the first and last authors were recorded. 
the authors, including the academic position of an author and whether the author is affiliated with the same lab as the last author. In some instances this information is obtained from the last author's web page but more commonly it comes from the web page for the last author's lab. Such web pages are particularly useful in identifying postdoctoral students, graduate students, undergraduate students, and staff scientists and technicians working in the lab. In cases where information could not be found (most frequently regarding the position of an author and whether the author has an affiliation with the last author's lab), missing values were coded. We believe this approach provides an accurate count of the number of students involved in the research. The count of postdocs is likely to be downward biased, however, since some postdocs, as noted earlier, have job titles that make it difficult to distinguish them from staff scientists. We thus view the postdoc count as a lower bound.

For papers having a last author affiliated with a non-US academic institution, we code only the field, number of authors, and location of the last author. Data on the fifty-one papers for which the last author is affiliated with a nonacademic institution, such as a private business, nonprofit organization, or government agency, were not collected regardless of country of last author. ${ }^{32}$ All told, data on 267 academic papers was collected. Of these, 159 had a last author at a US academic institution and 108 at a foreign academic institution. The distribution of papers by last author affiliation is summarized in table 4.1.

The median number of authors for US academic papers is five, the minimum is one, and the maximum is seven. Web pages could be found either for the last author's lab or for the last author in all but one case.

The last authors come from sixty-nine different US academic institutions. The largest number of last authors (sixteen) come from either Harvard or Harvard Medical School; nine come from UC Berkeley, eight from Stanford, and six from the University of Michigan Ann Arbor or the University of Michigan Medical School. Five institutions have scientists publishing five articles during the six-month time period. The institutions are: California Institute of Technology, Johns Hopkins, MIT, University of Michigan-Ann Arbor, University of Washington, and Yale. Several lesser-known institutions are represented, such as Minnesota State University Mankato, Franklin and Marshall College, and Georgia Southern University.

The distribution of US academic articles by area is given in table 4.2. The distribution mirrors Science's overall editorial practice of having a 60/40 split between the life and physical sciences. The median number of authors is highest in genetics; it is lowest in chemistry and neurology. The most authors were on a paper in biology.

32. Of these fifty-one papers, thirty-six have a US address; four have a German address; three have a Japanese address. The remaining eight are authored by individuals in Australia (1), Canada (2), France (2), Iceland (1), the Netherlands (1), and the United Kingdom (1). 
Table 4.1

Distribution of Science papers by last author affiliation

\begin{tabular}{lcccc}
\hline $\begin{array}{l}\text { Number of } \\
\text { issues coded } \\
\text { of articles } \\
\text { in issues }\end{array}$ & $\begin{array}{c}\text { Number for whom } \\
\text { last author has } \\
\text { a nonacademic } \\
\text { affiliation }\end{array}$ & $\begin{array}{c}\text { Number for whom } \\
\text { last author has } \\
\text { an academic } \\
\text { affiliation }\end{array}$ & $\begin{array}{c}\text { Number for whom } \\
\text { last author has } \\
\text { a US academic } \\
\text { affiliation }\end{array}$ \\
\hline 318 & 51 & 267 & 159 \\
\hline
\end{tabular}

Source: Authors (see chapter introduction for further information).

Table 4.2

Science articles by field

\begin{tabular}{lcccc}
\hline Area & $\begin{array}{c}\text { Number } \\
\text { of articles }\end{array}$ & $\begin{array}{c}\text { Median } \\
\text { number of } \\
\text { authors }\end{array}$ & $\begin{array}{c}\text { Minimum } \\
\text { number of } \\
\text { authors }\end{array}$ & $\begin{array}{c}\text { Maximum } \\
\text { number of } \\
\text { authors }\end{array}$ \\
\hline Biochemistry & 21 & 5 & 3 & 15 \\
Biology & 34 & 6 & 1 & 71 \\
Chemistry and related & 9 & 4 & 2 & 9 \\
Earth sciences & 16 & 5 & 1 & 22 \\
Genetics & 16 & 7 & 3 & 42 \\
Material science & 8 & 5 & 3 & 10 \\
Nano-related & 6 & 5.5 & 3 & 15 \\
Neurology & 12 & 4 & 2 & 14 \\
Physics & 17 & 5 & 2 & 11 \\
Other & 20 & 5 & 4 & 14 \\
\hline
\end{tabular}

Source: Authors.

\subsubsection{Authorship Patterns}

We first discuss the data for the 133 articles having nine or fewer authors; we then summarize the data for all US papers regardless of number of authors, focusing on an analysis of first and last author.

The data for articles with nine or fewer authors is summarized in table 4.3. Of the 648 authors, 585 lived in the United States. ${ }^{33}$ We could find information on the position of 550 of these (94.0 percent). Of these, 123 were postdocs (22.4 percent); another 108 (19.6 percent) were graduate students; eight ( 1.5 percent) were undergraduate students; and eight (1.5 percent) were students or postdocs, specific status not known. An additional four were alumni of the program, having either been a graduate student or a postdoc. ${ }^{34}$ The postdoc count is, as we noted before, an undercount in all likelihood given that some postdocs have titles that make it difficult to distinguish them from staff scientists. When the categories are combined, we find that almost

33. In several cases the individual is listed with two affiliations; one is in the United States; the other is outside the United States. In this case we count the individual as being in the United States.

34. This is an undercount of alums given that not all web pages list alumni of the program and in some instances faculty do not keep web pages. 
Table 4.3

Descriptive data for articles with less than 10 authors (133)

Total number of authors

Total number of authors in United States

Total number of US authors for whom position is known $\quad 550$

Total number postdocs

Total number of graduate students

Total number of undergraduate students

Total student (grad or undergrad) or postdoc; status/unknown

Total affiliated with lab in past

Number of papers with one or more author who is a postdoc, grad student, or undergraduate student

Source: Authors.

one out of two authors (45.6 percent) was a postdoc, a student, or a recent alum of the program. ${ }^{35}$

Of perhaps more interest to our study is the fact that 115 (86.5 percent) of this class of papers had either a current postdoc or student as one of the authors. Five of the eighteen papers that have neither postdocs nor students as coauthors are either singly authored or have only one US author. Two of the eighteen papers were in the field of astronomy, three in earth sciences, and two in material sciences. The field least likely to have either a postdoc or a student as a coauthor is astronomy (two for two), followed by material science (with two of the seven papers having neither a postdoc nor a graduate student author), and earth sciences (three of the thirteen had neither a postdoc nor a graduate student author). The fields most likely to have a postdoc or a graduate student as a coauthor are biochemistry, genetics, nano-related, and chemistry and chemistry-related. Indeed, all of the forty-two papers published in these four areas (with less than ten authors) had one or more graduate students or postdocs as co-authors. Fields not far behind are biology (twenty-seven of twenty-eight papers) and physics (eleven of twelve).

All but twenty-seven of the papers with less than ten authors have one or more authors working in the same lab as the senior US author. ${ }^{36}$ These patterns differ by field. The earth science papers are the least likely to have another individual working in a lab with the senior author (six out of thirteen earth science papers have no overlap in address). By way of contrast, 90 percent or more of the articles in biochemistry, genetics, nano-related areas,

35. A third of the postdocs are the only postdoc author on the paper; another third share authorship with one other postdoc; and another third share authorship with more than one other postdoc. Two papers have five postdocs as authors; twelve papers have three postdoc authors.

36. Five of these twenty-seven papers have only one US author. In some instances the PI does not have a lab. We include these instances in this count. 


\begin{tabular}{|c|c|c|c|}
\hline & $\begin{array}{l}\text { All US } \\
\text { articles }\end{array}$ & $\begin{array}{l}\text { First author (restricted } \\
\text { to counts for articles } \\
\text { having more than } \\
\text { one author) }\end{array}$ & $\begin{array}{c}\text { Last } \\
\text { author }\end{array}$ \\
\hline Number of US papers & 159 & 157 & 159 \\
\hline Number of authors in United States & 300 & 141 & 159 \\
\hline Total number of US authors for whom position is known & 291 & 136 & 155 \\
\hline Total number of postdoc authors & 59 & 57 & 2 \\
\hline Total number of graduate student authors & 45 & 41 & 4 \\
\hline Total number of undergraduate student authors & 1 & 0 & 1 \\
\hline Student/postdoc; exact status unknown & 4 & 4 & 0 \\
\hline
\end{tabular}

Source: Authors.

neurology, and physics have at least one co-author working in the same lab as the senior author.

Only eleven of the 115 papers with a postdoc or graduate student as a coauthor have no authors that are in the same lab as the senior US author. But it does not follow that all of the postdoc and student authors work in the lab of the last author. In a number of instances they work outside this lab, either with someone else at the same university or with someone in another university.

First and last authorship patterns are summarized in table 4.4 for all US academic articles appearing during the six-month period. The role of postdocs and students is especially striking when one looks at first-author position, a position of particular importance since in most fields the first author does the "heavy lifting," contributing the most to the article ${ }^{37}$ Fully 75 percent of the 136 first authors who are from the United States and whose position is known are either a postdoc or a student. Seven of the last authors are either a postdoc or a student. Four of these papers are in the area of earth science, further confirmation that the earth sciences are organized somewhat differently than the other fields we are looking at. Two of the papers that have postdocs as last author are in biochemistry. One paper in physics has an undergraduate student, Jacob Simones from the Minnesota State University Mankato, as the last author. The article has ten other authors, including his undergraduate advisor. Simones appears to have done related work during

37. Authorship patterns vary by discipline. In the life sciences the last author is generally the PI and the one who supplied the resources. The first author is the one who contributed the greatest amount to the research. This pattern is also true in chemistry and can also be the pattern in physics. In some disciplines, such as the earth and environmental sciences, authorship order is arranged entirely in terms of contribution. Authors are rarely listed in alphabetical order on scientific papers. For example, only twenty-six of the 159 papers we identified listed authors alphabetically; nineteen of these papers had only two authors, implying that there was a 50 percent chance of their being alphabetical regardless of practice. 
the summer of 2006 as a research experience for undergraduates (REU) at Minnesota State University funded by NSF. ${ }^{38}$

\subsubsection{Ethnicity of US Authors}

Ideally, we would like to know the citizenship status or birth origin of the students and postdoc co-authors. Short of fielding a survey this is not possible, because most postdocs and students do not put curriculum vitae's (CV's) on the web. Instead, we follow the approach used by Bill Kerr, drawing on the same ethnic-name database that he used to identify the ethnicity of US inventors (Kerr 2008).

Specifically, ethnicity is identified using data that Kerr obtained from the Melissa Data Corporation..$^{39}$ The Melissa data is particularly strong at identifying Asian ethnicities, especially Chinese, Indian/Hindi, Japanese, Korean, Russian, and Vietnamese names. In addition to the Asian ethnicities, we are able to distinguish four other ethnicities: Russian, English, European, and Hispanic. ${ }^{40}$ The approach exploits the idea that authors with "the surnames Chang or Wang are likely of Chinese ethnicity, those with surnames Rodriguez or Martinez of Hispanic ethnicity and so on" (Kerr 2007).

The methodology uses both first and last names and thus minimizes ambiguity in assigning names with multiple ethnicities, such as Lee and Park. Using ethnic names to identify citizenship status of graduate students and postdocs clearly has some limitations. If Asian and Hispanic names are classified as being foreign, the technique will overcount the foreign representation, given the number of US citizens with Asian and Hispanic names. On the other hand, if English and European names are used to classify individuals as "native," the native count will be overstated, given the number of European, English, and Canadian students and postdocs working in the United States.

Some indication of the degree of bias is given by examining the ethnicity of $\mathrm{PhD}$ recipients in the United States and the country of origin of $\mathrm{PhD}$ recipients who are noncitizen (either permanent or temporary resident). For example, in 2006, 1,164 PhDs in S\&E were awarded to US citizens who self-identify as being "Asian" (Falkenheim 2007, table 2). Concurrently, 7,918 $\mathrm{PhDs}$ were awarded to non-US citizens (permanent and temporary

38. See http://www.physics.umn.edu/outreach/reu/REU2006Proceed.pdf for papers by the REU interns.

39. We are grateful to Bill Kerr not only for providing us access to the database but also for doing the actual match.

40. In some instances, the matching procedure attributes a name to several ethnicities, providing the probability of ethnicity associated with each match. In these instances we coded the ethnicity that had a greater than 50 percent probability. By way of contrast, Kerr (2008), who has a significantly larger database and addresses different questions, summed probabilities associated with an ethnicity rather than assuming a specific ethnicity in cases that he refers to as "ties." 
visas) from the Asian countries of China, India, Korea, Japan, and Thailand (Falenkeim 2007, table 4). Assuming that citizens who self-identify as "Asian" have Asian last names leads to the conclusion that 13 percent of all $\mathrm{PhD}$ degrees awarded in the United States to individuals with Asian names went to citizen graduate students; 87 percent went to foreign graduate students. We cannot make a similar calculation for postdocs, given that neither the ethnicity of postdocs nor the source country of postdocs is ascertained. But we have reason to believe that the 87 percent is an undercount, given that not only among US $\mathrm{PhD}$ recipients is the postdoc-taking rate for noncitizen Asians high (Stephan and Ma 2005) but, in addition, a large percent of postdocs receive their PhDs outside the United States. Many of these, we assume, are Asian.

We estimate that approximately 1,132 PhDs in S\&E were awarded to nonUS citizens from English and European countries in $2005 .{ }^{41}$ Using "white" as synonymous with "English" and "European" and noting that the number of S\&E degrees awarded to "white" citizens in 2005 was 12,514 (Hoffer et al. 2006, table 8), we "guesstimate" that 8 percent of the English and European $\mathrm{PhD}$ names belong to noncitizens. In a similar way we "guesstimate" that 40 percent of Hispanics receiving degrees are noncitizens. ${ }^{42}$ In light of our counts, taken together, these "biases" come close to canceling each other out and we believe that we have fairly reasonable overall counts for noncitizen PhD students by "keying" on ethnicity of name if we classify English and European as "native" and all others as foreign. We believe this undercounts the total number of noncitizens among postdoctorates, given the large number of individuals who come with $\mathrm{PhD}$ in hand to take a postdoc position as well as the large number of noncitizen $\mathrm{PhD}$ recipients who stay in the United States for postdoctoral training.

It is more difficult to ascertain the magnitude of the bias for positions such as faculty and staff scientist. For our purposes, however, we will use the same convention as that noted previously.

The ethnicity of US authors on papers with less than ten authors is presented in table 4.5 by position. We identified no Vietnamese authors and

41. The NSF provides data on the top thirty countries of origin of non-US citizens earning doctorates regardless of field (Hoffer et al 2006, Table 12). We classify three of these countries as English: Australia, Great Britain, and Canada. The total number of $\mathrm{PhD}$ recipients from these countries is 800 . We classify three as "European:" Germany, Italy, and France; the number of recipients from the three is 581 . We estimate that $82 \%$ of all doctorate degrees awarded to non-citizens in the U.S. are in S\&E (Hoffer et al 2006, Table 11). From this, we estimate that 1,132 PhDs were awarded in S\&E to individuals who have European or English names and are non-US citizens.

42. We classify four countries in the "top 30 countries" list as "Hispanic," (Hoffer et al. 2006, table 12). These are Mexico, Colombia, Argentina, and Spain. Collectively, $618 \mathrm{PhDs}$ were awarded to individuals from these countries. We estimate that 82 percent of these are awarded in S\&E (507), using data from table 11 (Hoffer et al. 2006). There were 744 degrees awarded in S\&E to citizens who self-identify as Hispanic (Hoffer et al. 2006, table 8). From these two figures we "guesstimate" that 41 percent of the degrees awarded to Hispanics are to noncitizens. 


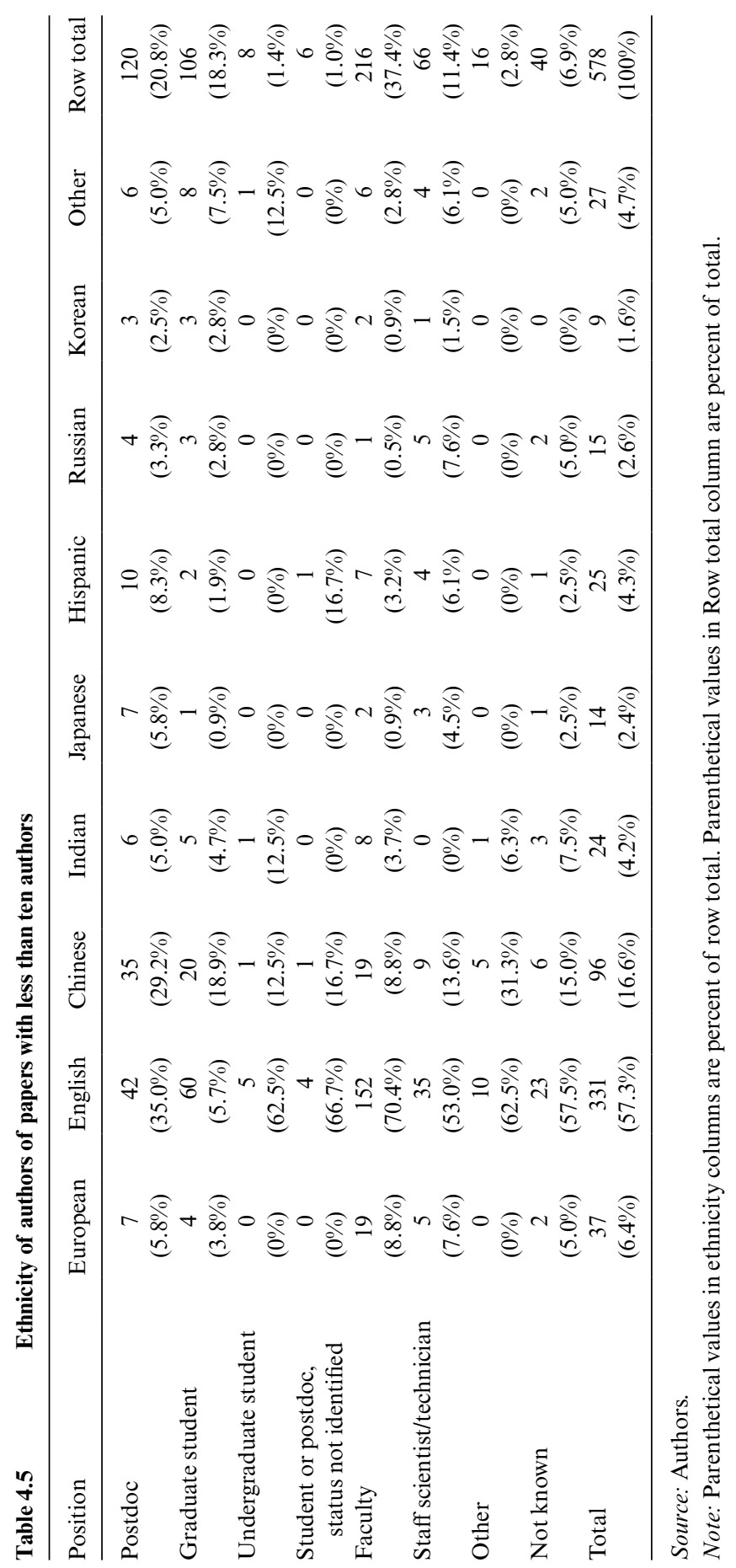


hence this category is not included in the table. "Other" refers to ethnicities not contained in the Melissa data. ${ }^{43}$

We find that 57.3 percent of authors with a US address (and writing with a last author at a US institution of higher education) are identified as having English names and 6.4 percent have European names. We find that 4.3 percent have Hispanic names, 16.6 percent have Chinese names, and 4.2 percent have Indian/Hindi names. Koreans, Japanese, Russians, and "other" make up the remaining 11.3 percent.

Of particular interest to our study is that seventy-one of the 120 postdoc authors are neither English nor European (59.2 percent). This is remarkably close to the 60 percent that NSF estimates for $2006 .{ }^{44} \mathrm{We}$ find that forty-two of the 106 graduate student co-authors have neither English nor European names (39.6 percent). This is slightly lower than the percent of US PhDs awarded in science and engineering to noncitizen PhDs in 2006 (Falkenheim 2007, table 2), but consistent with the finding of John Bound and Sarah Turner (chapter 3, this volume) that higher-ranked institutions (from which most of these authors are drawn) have a lower proportion of foreigngraduate students than do lower-ranked institutions. We note that a large percent of the faculty authors are English or European (79.2 percent); the next most likely ethnic group to be a faculty author is Chinese (8.8 percent). We also classify authors according to whether they are a staff scientist or a technician. We find that slightly more than 60 percent of authors in such positions have English or European names; 13.6 percent have Chinese names.

Focusing on articles, we find that seventy of the 133 papers ( 53 percent) with fewer than ten US authors have a foreign student or postdoc as a coauthor. This represents approximately 60 percent of the 115 papers that have either a student or a postdoc author. We infer that it is the norm, not the exception, to have an international student or postdoc as a coauthor in papers published in Science.

Table 4.6 shows position and ethnicity for US first authors from our sample of all papers. We find that 55.7 percent are either of English or European ethnicity, the remaining 44.3 percent are "foreign"- 17.9 percent are Chinese, 7.9 percent are Indian/Hindi, 4.3 percent are Hispanic, and 14.3 percent are drawn from other ethnicities. The heavy representation of graduate students and postdocs in the first-author position has already been noted. But what we learn from this table is the important role of "foreign" graduate students and postdocs. To wit, using our convention, we find that almost 60 percent of the graduate student first authors are foreign - a figure significantly higher than the percent of noncitizen $\mathrm{PhD}$ recipients in science

43. The database used for the ethnicity match contained several edits that were not present in the database used in creating tables 4.1 through 4.4 . Thus, while the counts in the ethnicity tables are very close to those in the earlier tables, they do not always correspond perfectly.

44. Note that NSF calculations classify "permanent residents" with US citizens in determining citizenship status of postdocs. 


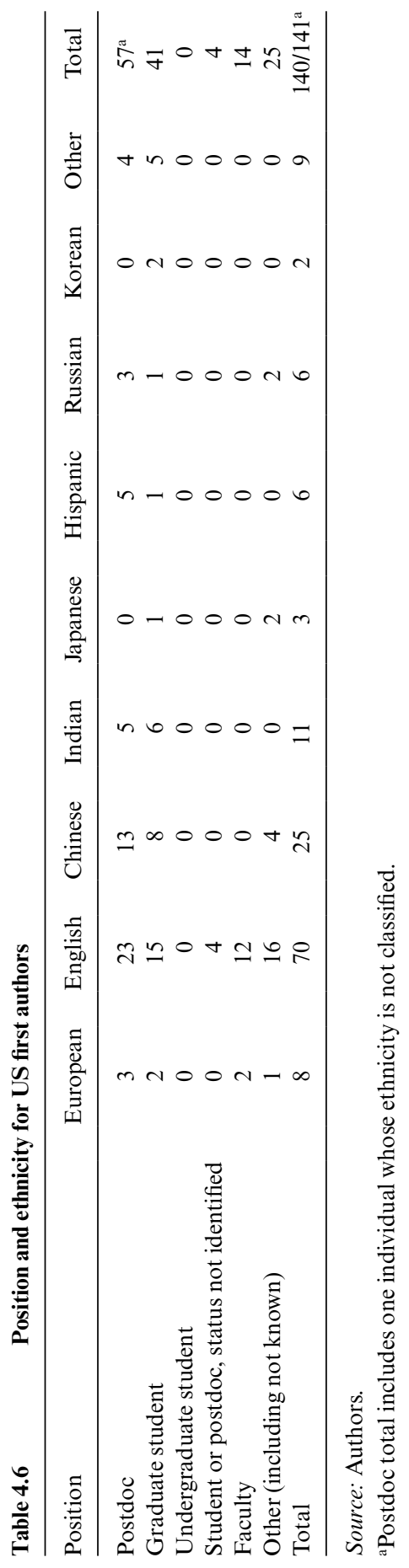


and engineering and higher than the percent of "foreign" graduate students among graduate student coauthors in general (table 4.6). Noncitizens also make up slightly more than 54 percent of the first-author postdocs. Clearly, international graduate students and postdocs are important not only in staffing labs; they play lead roles in research. It is also interesting to note that faculty play a relatively minor role as first author, while staff scientists and technicians play a relatively important role (other category).

The position and ethnicity for last authors is given in table 4.7. It is of less interest to our study, given the small role that graduate students and postdocs play as "last authors." Briefly, and using the same convention, we note that 73.6 percent of last authors are "native"; 26.4 percent are foreign. Fully one third of the "foreign" last authors are Chinese.

Our findings regarding nativity are summarized in table 4.8. Slightly more than 44 percent of first authors are foreign; almost 60 percent of postdoc authors are foreign. Last authors are very likely to be native (over 73 percent) and six out of ten graduate student authors are native.

Finally, in table 4.9, we examine "affinity effects" by comparing the ethnicity of the last author to the ethnicity of coauthors working in the United States for all papers with less than ten authors. Proceeding in such a manner, we find that 73.8 percent of the coauthors of English last authors are English. If non-last authors were distributed randomly across articles, we would expect it to be 54.5 percent, based on the distribution in our database of authors. In a similar manner, we find that 53.8 percent of the coauthors of Chinese last authors are Chinese - a figure that is strikingly higher than the 18.6 percent that we would expect. Affinity effects also appear to be present for Hispanics but the cell sizes are very small. We find no evidence of affinity effects for European last-authors.

\subsection{Conclusion}

\subsubsection{Summary of Findings}

Universities play an important role in the production of knowledge in the United States, authoring nearly 75 percent of scientific and engineering articles written within the country. Within the university, research is often performed with the assistance of graduate students, postdoctoral scholars, and staff scientists, many of whom are foreign-born and, in the case of graduate students and postdocs, are studying in the United States on temporary visas.

Here we document the important role played by students and postdocs in university research by analyzing authorship patterns for a six-month period for articles published in Science having a last author affiliated with a US university. We choose Science because of its multidisciplinary nature and its position as a leading, if not the leading, journal in science. The fast 


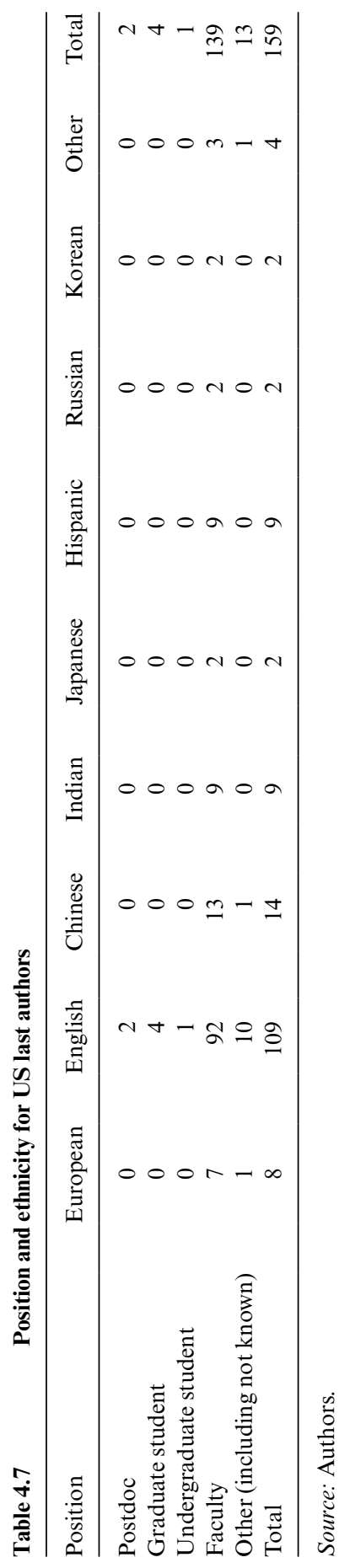


Table 4.8

Authorship patterns by nativity (percent)

\begin{tabular}{lcc}
\hline Position & Native & Foreign \\
\hline First authors & 55.7 & 44.3 \\
Last authors & 73.6 & 26.4 \\
Postdoc authors & 40.8 & 59.2 \\
Graduate students & 60.4 & 39.6 \\
\hline
\end{tabular}

Source: Authors.

Table 4.9

Affinity effects in authorship patterns

\begin{tabular}{lccc}
\hline Ethnicity of last author & $\begin{array}{c}\text { Expected percent } \\
\text { of coauthors with } \\
\text { same ethnicity }\end{array}$ & $\begin{array}{c}\text { Actual percent of } \\
\text { coauthors with } \\
\text { same ethnicity }\end{array}$ & $\begin{array}{c}\text { Number } \\
\text { of papers }\end{array}$ \\
\hline English & 54.5 & 73.8 & 88 \\
Chinese & 18.6 & 53.8 & 13 \\
Indian & 3.4 & 5.5 & 9 \\
European & 6.7 & 0.0 & 7 \\
Hispanic & 4.3 & 23.3 & 6 \\
\hline
\end{tabular}

Source: Authors.

turnaround time (decisions are generally made in less than a month and publication rapidly follows) also means that we are able to do web research regarding the status of authors.

We analyze authorship patterns for two sets of papers: (a) papers having fewer than ten authors, in which case we determine the status of all authors residing in the United States; and (b) all papers regardless of the number of authors, in which case we determine the status of the first and the last author. The first data set contains 133 articles; the second data set contains 159 papers. We determine the status of each author with a US affiliation through web-based research, starting with the last author's web page, which often contains a link to the lab and the group working in the lab. We find the web to be a powerful tool: of the 585 US authors we can determine the status of 550. We believe we are the first to use such a methodology to investigate the role that students and postdocs play in research. ${ }^{45}$

Our analysis demonstrates the important role that students and postdocs play in university research. We find that 45.6 percent of all authors, or almost one out of two, is a postdoc, student, or a recent alum of the program. By category, 22.4 percent are postdocs, 19.6 percent are graduate students, 1.5 percent are undergraduate students, another 1.5 percent are student or postdoc (status not known), and a handful are alums of the program. What is even more indicative of the important role that students 
and postdocs play in university research is our finding that 86.5 percent of papers - nearly seven out of eight (133-paper sample) - have either a current postdoc or student as one of the authors.

The role of postdocs and students is especially striking when one looks at first-author position on all US papers, regardless of the number of authors. To wit, we find that 102 of the 136 first authors who are in the United States and whose position is known are either a postdoc or a student ( 75 percent); seven of the last authors are either a postdoc or a student.

We identify the ethnicity of authors, drawing on the ethnic-name database that Kerr (2008) used to identify ethnicity of US inventors. The methodology is particularly strong at identifying Asian ethnicities. This approach clearly has some limitations. If Asian and Hispanic names are classified as being foreign, the technique overcounts the foreign representation, given the number of US citizens with Asian and Hispanic names. On the other hand, if English and European names are used to classify individuals as "native," the native count will be overstated, given the number of European, English, and Canadian students and postdocs working in the United States. We draw upon the distribution of $\mathrm{PhDs}$ awarded in 2006 to investigate the degree of this bias. We conclude that approximately 87 percent of the Asians we identify are noncitizens; 8 percent of the English and Europeans we identify are noncitizens; and 40 percent of the Hispanics are noncitizens. In light of our counts, these "biases" approximately cancel each other out and we believe that we get fairly reasonable overall counts for noncitizen $\mathrm{PhD}$ students and postdocs by "keying" on ethnicity of name and defining "English" and "European" as native.

Using this approach, we find that 59.2 percent of postdoc authors are neither English nor European, a figure that is remarkably close to the 60 percent that NSF estimates. We find that 39.6 percent of the graduate student co-authors have neither English nor European names. This is slightly lower than the percent of PhDs awarded in science and engineering to noncitizens in 2006. At the paper level, we find that seventy of the 133 papers (53 percent) with fewer than ten US authors have a foreign student or postdoc as a co-author. This represents approximately 60 percent of the 115 papers that have either a student or a postdoc author. Clearly, it is the norm, not the exception, to have an international student or postdoc as a co-author in papers published in Science.

Using the same convention, we find that almost 60 percent of the graduate student first authors are foreign and that noncitizens make up slightly more than 54 percent of the postdocs who are first authors. We conclude that international graduate students and postdocs are important not only in staffing university labs; they play lead roles in university research.

\subsubsection{Discussion}

It has long been known that the foreign-born play an important role in US science and engineering. The basis for much of this understanding has 
been the role the foreign-born play as faculty or when working in industry. The results of the present study suggest that the foreign-born play an important role in doing research, much of which is of a basic nature, while they are graduate students and postdocs. The finding is not surprising, but prior to this study no one has set about to investigate the degree to which the foreign-born contribute in this way.

The contributions of the foreign-born graduate students and postdoctoral scholars to US science, of course, do not end when their training is completed. Many choose to stay in the United States. Finn, for example, finds that approximately 70 percent of $\mathrm{PhD}$ recipients on temporary visas in science and engineering were in the United States two years after receiving their $\mathrm{PhD}$ degree; the five-year stay rate was only slightly lower (Finn 2005, table 3). The rate is highest for Chinese, who have a five-year stay rate of 90 percent, followed by Indians, with a five-year stay rate of 86 percent. (Finn 2005, table 7.) No one has made comparable estimates for postdocs, but the assumption is that a number who come to train stay on after their training is completed. The ethnicity of faculty authors in this study is suggestive of this; approximately one in five had neither English nor European names. The group making up the highest percent of nonnative faculty was of Chinese ethnicity.

This is not to say that scientists and engineers contribute to US science only when they stay. Many who return end up co-authoring papers with colleagues in the United States. We see some examples of this in our data. The work of Adams et al. (2005) finds that the international co-authorship patterns of faculty at US universities are influenced by the number of foreign students trained in their department who return to their home country. Moreover, co-authorship is not the only way by which scientists in one country benefit from the work and expertise of others. Published science is a public good; regardless of whether they stay or leave, these researchers will continue to contribute to the creation of knowledge.

That foreign-born graduate students and postdoctoral fellows play an important role appears indisputable from this research. But it does not follow that their places would be left unfilled if they were not to come. Considerable debate has focused on the degree to which foreign-born students displace US students. The question is difficult to answer but there is reasonable agreement regarding several facts. First, natives, especially native males, when choosing a career are responsive to alternative opportunities. In the last twenty or so years many of these opportunities - for example, law and business - have proved relatively more attractive, requiring shorter training times and offering higher salaries. Second, if the incentive structure were to change, the number of US citizens entering $\mathrm{S} \& \mathrm{E}$ would arguably change as well. By way of example, Richard Freeman (2005) finds the size of the applicant pool for NSF Graduate Research Fellowships to be responsive to the relative value of the stipend and concludes "that the supply of highly skilled applicants is sufficiently responsive to the value of awards that increases in 
the value of stipends could attract some potentially outstanding science and engineering students who would otherwise choose other careers." Third, and by way of contrast, foreign-born have had fewer alternatives available that offer the option of support while in school and employment at a favorable relative wage. Fourth, the alternatives open to the foreign-born are changing. Programs outside the United States are becoming more and more competitive. Since the late 1980s the number of S\&E PhD degrees awarded in Europe has surpassed the number in the United States. In the late 1990s, the number of degrees awarded in Asian countries surpassed the number awarded in the United States. In China alone the number accelerated from virtually zero in 1985 to approximately 13,500 by 2004 (National Science Board 2008, appendix tables 2-42 and 2-43). At the same time, programs in the United States are at risk of becoming less attractive to foreign-born students and postdoctoral scholars. This is not only because funds for graduate and postdoctoral support are diminishing as agencies such as NIH experience real decrease in funding levels, but also because of problems faced by foreign nationals in the United States since 9/11. A case in point is the special vetting required for foreign nationals to work on research supported by federal agencies and considered "sensitive but unclassified." 46

Nor does it follow that the demand for graduate students and postdocs to work at universities will necessarily persist at its current level. The technology of discovery is changing. By way of example, in 1990 the best-equipped lab could sequence 1,000 base pairs a day. By January 2000 the twenty labs involved in mapping the human genome were collectively sequencing 1,000 base pairs a second, 24/7. The cost per finished base pair fell from $\$ 10.00$ in 1990 to under \$.05 in 2003 (Collins, Morgan, and Patrinos 2003) and was roughly $\$ .01$ in 2007 (http://biodesign.asu.edu/news/nih-funds-next-gener ation-of-dna-sequencing-projects-at-asu). As the technology of discovery changes, the need for skilled lab workers-many of whom are graduate students and postdocs - may decline. Moreover, as equipment becomes increasingly sophisticated and more expensive, research procedures may increasingly be outsourced to nonuniversity facilities. Mail-in crystallography, where crystals are sent to large nonuniversity labs for analysis, is but one example. There is also the question of whether the Federal government will continue to provide resources for graduate research assistants and postdocs at the level it has in the past.

The heavy reliance on graduate students and postdoctoral scholars in the performance of university research has contributed to the US eminence as a training center for both native and foreign-born students. It provides not only hands-on learning but also financial support for graduate study and

46. This may change in the near future. In June of 2008 DOD Under Secretary John Young wrote a directive stating that "classification is the only appropriate mechanism" for restricting participation by foreign nationals or for restricting publication (Bhattacharjee 2008, 325). 
postdoctoral work, something that many other countries cannot provide. Factors that reduce either the demand for or supply of graduate students and postdocs have the potential of threatening the United States's eminence as a training center and producer of research.

\section{References}

Adams, J. D., G. C. Black, R. Clemons, and P. Stephan. 2005. Scientific teams and institutional collaborations: Evidence from US universities, 1981-1999. Research Policy 34 (3): 259-85.

Andrews, F. M., ed. 1979. Scientific productivity: The effectiveness of research groups in six countries. Cambridge: Cambridge University Press.

Agrawal, A., and A. Goldfarb. 2008. Restructuring research: Communication costs and the democratization of university innovation. American Economic Review 98 (4): $1578-90$.

Barnett, A., R. W. Ault, and D. Kaserman. 1988. The rising incidence of coauthorship in economics: Further evidence. Review of Economics and Statistics 70 (3): $539-43$.

Bhattacharjee, Y. 2008. New policy tries to ease security restrictions. Science 321 (5887): 325.

Bunton, S. A., and W. T. Mallon. 2007. The continued evolution of faculty appointment and tenure policies at US medical schools. Academic Medicine 82 (3): 281-89.

Collins, F., M. Morgan, and A. Patrinos. 2003. The human genome project: Lessons from large-scale biology. Science 300 (5617): 286-90.

Davis, G. 2005. Doctors without orders. American Scientist 93 (3, supplement). Available at: http://postdoc.sigmaxi.org/results/.

Ehrenberg, R. G., M. J. Rizzo, and G. H. Jakubson. 2003. Who bears the growing cost of science at universities? NBER Working Paper no. 9627. Cambridge, MA: National Bureau of Economic Research, April.

Falkenheim, J. 2007. US doctoral awards in science and engineering continue upward trend in 2006. InfoBrief, Science Resources Statistics, National Science Foundation (NSF).

Finn, M. G. 2005. Stay rates of foreign doctorate recipients from US universities, 2003. Oak Ridge, TN: Oak Ridge Institute for Science and Education.

Fox, M. F. 1991. Gender, environmental milieu, and productivity in science. In The outer circle: Women in the scientific community, ed. H. Zuckerman, J. R. Cole, and J. T. Bruer, 188-204. New York: W. W. Norton.

Franzoni, C., G. Scellato, and P. Stephan. 2008. Changing incentives to publish and the consequences for submission patterns. Paper prepared for presentation at the Dynamics of Institutions and Markets in Europe (DIME)-BRICK workshop, "The Economics and Policy of Academic Research." July, Collegio Carlo Alberto, Moncalieri (Torino), Italy.

Freeman, R. B., T. Chang, and H. Chiang. 2005. Supporting "The Best and the Brightest" in science and engineering: NSF graduate research fellowships. NBER Working Paper no. 11623. Cambridge, MA: National Bureau of Economic Research, September.

Hoffer, T., K. Grigorian, and E. Hedbert. 2008. Postdoc participation of science, engineering, and health doctorate recipients. InfoBrief, (NSF), March. 
Hoffer, T. B., V. Welch, Jr., K. Webber, K. Williams, B. Lisek, M. Hess, D. Loew, and I. Guzman-Barron. 2006. Doctorate recipients from United States universities: Summary report 2005. Chicago: National Opinion Research Center.

Jones, B. 2005. The burden of knowledge and the "death of the renaissance man": Is innovation getting harder? NBER Working Paper no. 11360. Cambridge, MA: National Bureau of Economic Research, May.

Kean, S. 2006. Scientists spend nearly half their time on administrative tasks, survey finds. Chronicle of Higher Education, July 7.

Kerr, W. R. 2007. The ethnic composition of US inventors: Evidence building from ethnic names in US patents. Paper prepared and presented at NBER workshop on Career Patterns of Foreign-Born Scientists and Engineers Trained and/or Working in the US, November 7, New Brunswick, NJ.

. 2008. Ethnic scientific communities and international technology diffusion. Review of Economics and Statistics 90 (3): 518-30.

Kolbert, E. 2007. Crash course: The world's largest particle accelerator. The New Yorker, May 14.

Lawani, S. M. 1986. Some bibliometric correlates of quality in scientific research. Scientometrics 9 (1-2): 13-25.

Malakoff, D. 2000. The rise of the mouse, biomedicine's model mammal. Science 288 (5464): $248-53$.

Mervis, J. 1998. The biocomplex world of Rita Colwell. Science 281 (5385): 1944-47. 2008. Top PhD feeder schools are now Chinese. Science 321 (5886): 185.

National Academies. 2005. Policy implications of international graduate students postdoctoral scholars in the United States. Committee on Policy Implications of International Graduate Students and Postdoctoral Scholars in the United States, Committee on Science, Engineering, and Public Policy. Washington, DC: The National Academies Press.

National Science Board. 2006. Science and engineering indicators 2006. Arlington, VA: NSB.

- 2008. Science and engineering indicators 2008. Arlington, VA: NSB.

National Science Foundation. WebCASPAR, Integrated Science and Engineering Resources Data System. Available at: http:/webcaspar.nsf.gov/.

Overbye, D. 2007. A giant takes on physics' biggest questions. New York Times, May 15.

Pelekanos, A. 2008. Money management for scientists: Lab budgets and funding issues for young pis. Science Alliance, New York Academy of Sciences, June 16.

Penning, T. 1998. The postdoctoral experience: An associate dean's perspective. The Scientist 12 (19): 9.

Regets, M. 2005. Foreign students in the United States. Presentation at the Dialogue Meeting on Migration Governance: European and North American Perspectives. June 27, Brussels, Belgium.

2007. An overview of foreign-born S\&E workers in the United States and their measurement. Unpublished manuscript prepared for presentation at the NBER Conference on Career Patterns of Foreign-born Scientists and Engineers. November 7, New Brunswick, NJ.

Service, R. F. 2006. Tennessee scientists beaming. Science 312 (May): 675.

Stephan, P. E. 2008. Job market effects on scientific productivity. In Scientific competition, ed. M. Albert, D. Schmidtchen, and S. Voigt, 11-29. Tubingen, Germany: Conferences on New Political Economy 25, Mohr Siebeck.

Stephan, P. E., G. Black, and T. Chaing. 2007. The small size of the small-scale market: The early-stage labor market for highly skilled nanotechnology workers. Research Policy 36 (6): 887-92. 
Stephan, P. E., and S. G. Levin. 2002. The importance of implicit contracts in collaborative research. In The new economics of science, ed. P. Mirowski and E.-M. Sent, 412-30. Chicago: University of Chicago Press.

Stephan, P. E., and J. Ma. 2005. The increased frequency and duration of the postdoctorate career stage. American Economic Review Papers and Proceedings 95 (2): 71-75.

Tanyildiz, Z. E. 2008. The effects of networks on institution selection by foreign doctoral students in the US. Unpublished dissertation, Georgia State University.

Vogel, G. 1999. Working conditions: A day in the life of a topflight lab. Science 285 (5433): 1531-2.

Winkler, A., S. Levin, and P. Stephan. 2008. The diffusion of IT in higher education: Publishing productivity of academic life scientists. Andrew Young School of Policy Studies Research Paper Series no. 09-01.

Wuchty, S., B. Jones, and B. Uzzi. 2007. The increasing dominance of teams in the production of knowledge. Science 316 (5827): 1036-39. 